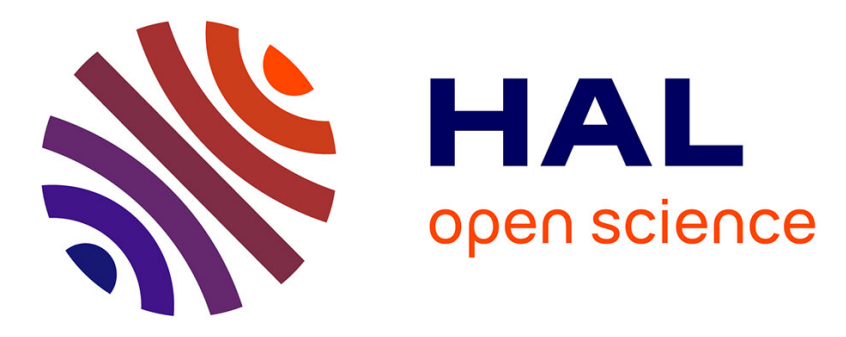

\title{
Hydraulic Resistance of Emergent Macroroughness at Large Froude Numbers: Design of Nature-Like Fishpasses
}

Ludovic Cassan, Tien Tran Dung, Dominique Courret, Pascale Laurens, Denis Dartus

\section{To cite this version:}

Ludovic Cassan, Tien Tran Dung, Dominique Courret, Pascale Laurens, Denis Dartus. Hydraulic Resistance of Emergent Macroroughness at Large Froude Numbers: Design of Nature-Like Fishpasses. Journal of Hydraulic Engineering, 2014, vol. 140 ( $\mathrm{n}^{\circ}$ 9), pp. 1-9. 10.1061/(ASCE)HY.19437900.0000910 . hal-01166268

\section{HAL Id: hal-01166268 \\ https://hal.science/hal-01166268}

Submitted on 22 Jun 2015

HAL is a multi-disciplinary open access archive for the deposit and dissemination of scientific research documents, whether they are published or not. The documents may come from teaching and research institutions in France or abroad, or from public or private research centers.
L'archive ouverte pluridisciplinaire HAL, est destinée au dépôt et à la diffusion de documents scientifiques de niveau recherche, publiés ou non, émanant des établissements d'enseignement et de recherche français ou étrangers, des laboratoires publics ou privés. 


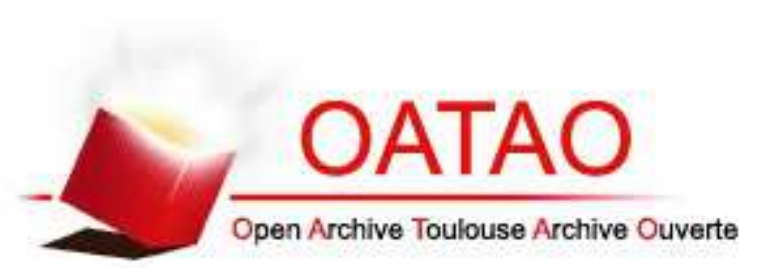

\section{Open Archive TOULOUSE Archive Ouverte (OATAO)}

OATAO is an open access repository that collects the work of Toulouse researchers and makes it freely available over the web where possible.

This is an author-deposited version published in : http://oatao.univ-toulouse.fr/ Eprints ID : 13861

To link to this article :

DOI: 10.1061/(ASCE)HY.1943-7900.0000910

URL: http://dx.doi.org/10.1061/(ASCE)HY.1943-7900.0000910

To cite this version : Cassan, Ludovic and Tran Dung, Tien and Courret, Dominique and Laurens, Pascale and Dartus, Denis Hydraulic Resistance of Emergent Macroroughness at Large Froude Numbers: Design of Nature-Like Fishpasses. (2014) Journal of Hydraulic Engineering, vol. 140 ( $n^{\circ}$ 9). pp. 1-9. ISSN 0733-9429

Any correspondance concerning this service should be sent to the repository administrator: staff-oatao@listes-diff.inp-toulouse.fr 


\title{
Hydraulic Resistance of Emergent Macroroughness at Large Froude Numbers: Design of Nature-Like Fishpasses
}

\author{
Ludovic Cassan ${ }^{1}$; Tran Dung Tien²; Dominique Courret ${ }^{3}$; Pascale Laurens ${ }^{4}$; and Denis Dartus ${ }^{5}$
}

\begin{abstract}
The mean flow in a nature-like fishpass can be highly modified by the Froude number. It is important to understand this evolution to correctly design the structure. The studied configuration is an emergent staggered arrangement of obstacles. The hydraulic resistance of a fishpass is experimentally investigated that depends on several geometric parameters: block shape, ramp slope, block density, and bed roughness. An analytical model based on the balance momentum allows one to quantify the influence of each hydraulic parameter. The bed roughness has a weak influence, whereas the block shape and the Froude number are significant. The variation of the drag coefficient was analyzed to improve the stage-discharge relationship. To this end, a correlation with the block diameter and water level is proposed. The maximal velocity reached in the fishpass can also be estimated. These results have to be compared with the fish swimming ability to assess the fishpass passability.
\end{abstract}

Author keywords: Nature-like fishpass; Flow resistance; High Froude number; Emergent block; Drag coefficient.

\section{Introduction}

Since the 1990s, restoration and protection plans for migratory fish species (salmon, sea trout, shad, and lamprey) have been implemented on French rivers. One type of project is to restore river longitudinal connectivity at obstacles (weirs, dams). In this context, fishpasses have usually been designed for species with good swimming capability. Most facilities are vertical-slot fishpasses (VSF) and baffle fishpasses (Larinier et al. 2002). Since the adoption of the European Water framework directive in 2000 (2000/60/ EC), ecological continuity, including the upstream migration of all species, has been identified as one of the hydromorphological elements that sustain the good ecological status of rivers. Naturelike fishpasses, i.e., those that attempt to reproduce the characteristics of natural rivers, are one of the solutions to achieve fish passage and thus contribute to good ecological status. They generally have steep slopes and consist of natural or prefabricated blocks that provide energy dissipation and reduce flow velocities. Nature-like fishpasses are likely to offer a wide range of flow conditions and can restore connectivity for most fish species, at least at the adult stage. Different types of block ramps are possible, e.g., (1) ramps with only a rough bed, (2) ramps with a rough bed and protruding blocks more or less evenly distributed, and (3) ramps with a rough bed and crossbar blocks forming pools

${ }^{1}$ Assistant Professor, Institut de Mecanique des Fluides, allee du Prof. Camille Soula, 31400 Toulouse, France (corresponding author). E-mail: lcassan@imft.fr

${ }^{2}$ Ph.D. Student, Water Resources Univ., 175 Tay Son, Dong Da Dist, Hanoi, Vietnam. E-mail: dtran2@imft.fr

${ }^{3}$ Engineer, ONEMA, allee du Prof. Camille Soula, 31400 Toulouse, France. E-mail: courret@onema.fr

${ }^{4}$ Assistant Professor, Institut de Mecanique des Fluides, allee du Prof. Camille Soula, 31400 Toulouse, France. E-mail: pascale.laurens@imft.fr

${ }^{5}$ Professor, Institut de Mecanique des Fluides, allee du Prof. Camille Soula, 31400 Toulouse, France. E-mail: dartus@imft.fr
(Oertel and Schlenkhoff 2012). In this paper, the fishpasses with a rough bed and protruding macroroughness evenly distributed in staggered rows are studied (Fig. 1). This solution is particularly interesting because the high flow enhances the attractiveness for fish and reduces the risk of clogging (large spacing between blocks) and silting (no pool). The design of these systems consists mainly of defining the number of protruding blocks, the slope of the ramp, and its position with respect to the water levels upstream and downstream of the obstacle, to obtain water depths and velocities adapted to the needs of the target species. Correct design implies a stagedischarge relationship for the preceding configuration suited to a wide range of slope and block arrangements. Previous work on similar configurations (Ferro 1999; Pagliara and Chiavaccini 2006) did not focus on the upstream movement of fish, nor did it explore a wide range of configurations (Heimerl et al. 2008). One aim of this study is to provide an appropriate stage-discharge relationship. The equations from studies on rigid obstacles (James et al. 2004; Nepf 1999), which also used a staggered block array, were employed. In this study, the slope and the Froude number are generally larger than those for emergent obstacles. For this reason, the model must take into account the deformation of the free surface and gravitational forces. Another difference is the value of bed friction, selected to ensure the upstream movement of various species. In the model, nature-like fishpasses are represented by an array of blocks evenly spaced on the longitudinal and transverse axes. The block center-to-center distance in the longitudinal and transverse direction are denoted, respectively, by $a_{y}$ and $a_{x}$. The blocks are defined by their characteristic length $D$ and height $k$. The average water depth is denoted by $h$. To remain consistent with previous work (Larinier et al. 2006), the density of block positioning is similar to a macroroughness concentration $C$, i.e., the ratio between the square of the length in front of the flow and the surface of a unit cell of the flow, where $C=D^{2} / a_{x} a_{y}$ (Fig. 1). The block shape is taken into account with the parameter $\sigma$, which is the ratio between the block area in the $x, y$ plane and $D^{2}$. The mean velocity $V=q / h$ is calculated as the flow rate per unit width $q$ divided by the average water depth $h$. It has been observed experimentally in arrangements of rigid obstacles that this rate is almost constant at all water depths (Rowinski and Kubrak 2002; Huai et al. 2009; Tinoco and Cowen 2013). As already observed by James et al. (2004), rigid-obstacle 


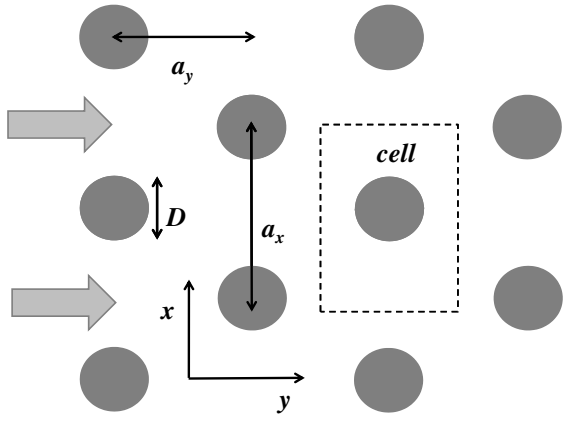

Fig. 1. Characteristic dimensions

models reproduce drag forces better when the average velocity between the blocks $\left(V_{g}\right)$ is taken into account. This velocity can be expressed in terms of the space between the blocks and the bulk velocity:

$$
\frac{V_{g}}{V}=\frac{1}{1-\sqrt{\frac{a_{y}}{a_{x}}} C}
$$

The next section presents the experimental results used to develop and validate the analytical model. In the subsequent sections, different flow patterns are described and a methodology is proposed to determine the deformation of the free surface and the maximum velocity of the stream. The analytical model based on the momentum balance is presented. Particular attention is paid to correcting the drag coefficient, which may differ between obstacles and fishpasses. The resulting stage-discharge relationship for a large range of macroroughness concentrations, bed forms, and Froude numbers is then presented.

\section{Experimental System}

Experiments were carried out with two channels with variable slope at the Institute of Fluid Mechanics (IMFT). The first channel was $0.25 \mathrm{~m}$ wide and $10 \mathrm{~m}$ long. The macroroughness consisted of cylinders $35 \mathrm{~mm}$ in diameter $D$ and $70 \mathrm{~mm}$ high. The slope ranged from $1 \%$ to $8 \%$, and measurements were performed under different flow conditions. Polyvinyl chloride was selected for the bed to produce the smoothest possible flow by minimizing roughness. To measure the mean water depth across the width of the channel, a plexiglass plate was inserted across the center of the channel perpendicular to the flow at middistance between two rows of block. The plexiglass plate was attached to a Mitutoyo Absolute digital water-level measuring device capable of precisely determining the position of the plate relative to the channel bottom.

The second channel was $1 \mathrm{~m}$ wide and $7 \mathrm{~m}$ long. The blocks were wooden cylinders $150 \mathrm{~mm}$ high and $115 \mathrm{~mm}$ in diameter (Fig. 2). Two macroroughness concentrations of $13 \%$ and $16 \%$ were tested. For each macroroughness concentration and each bed roughness, the slope ranged from $1 \%$ to $9 \%$. Measurements

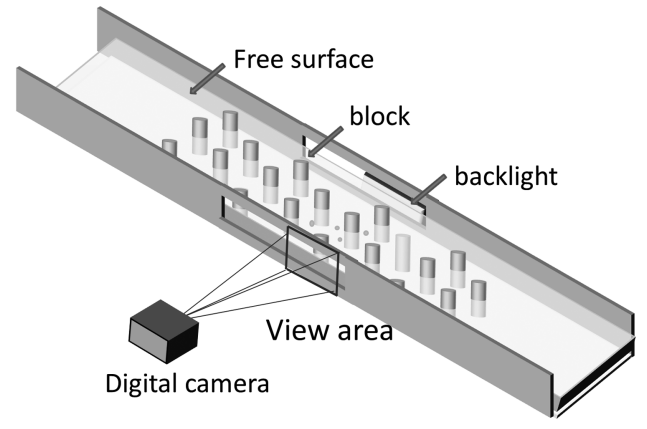

Fig. 2. Second experimental channel were carried out for different flow rates and water levels ( $Q$ varied from 10 to $90 \mathrm{~L} / \mathrm{s}, h$ varied from 0.04 to $0.2 \mathrm{~m}$, and $V_{g}$ varied from 0.2 to $1.2 \mathrm{~m} / \mathrm{s}$ ). The Reynolds and Froude numbers of the experiments can be found in Table 1 The pebbles used for bed roughness were between 30 and $50 \mathrm{~mm}$ in diameter. For two series of experiments (E2 and E3), the width was reduced to $650 \mathrm{~mm}$. These experiments were carried out to study the influence of block shapes. The E3 experiments were carried out with trapezoidal blocks with a flat side facing the flow. For the E2 experiments, a semicircular pipe was added to the trapezoidal blocks to create an intermediate case between circular and flat blocks. A PCO.2000 camera $(2,048 \times 2,048$ pixels $)$ was used to measure the free surface of a pattern using shadowscopy. A light-emitting diode lighting system made it possible to differentiate the air from the water. The imageacquisition frequency was $3 \mathrm{~Hz}$. A series of 600 images was taken for each flow. This number of images ensures a good convergence of the measured mean water depth $h$ (accuracy less than $0.5 \%$ ). The mean water depth was then obtained by averaging the signal for each pixel. As a consequence, the water level was also averaged across the channel. The free surface was identified by the signal minimum. The minimum and maximum water depths were then extracted (Figs. 3 and 4). The mean water depth of the cell was deduced by averaging the height of the free surface in the longitudinal direction. The measurement accuracy can be deduced from shadowgraph pictures; it is estimated to $+/-5 \mathrm{~mm}$. The flow rates were measured using KROHNE electromagnetic flow meters (accuracy $=0.5 \%$ ). When the width was reduced (E2 and E3 series), the water depth was measured using the technique implemented for the first channel. For rough flow, the bed position was obtained using the average height of the roughness $k_{s}$. The same length was used for the friction calculation [Eq. (15)] and for the adjustment in the bed position. Some of the velocity measurements were made with an electromagnetic current meter (E2 and E3) or with a miniature current flow meter (Streamflo, NIXON Instrumentation) (E8-E10). Velocity was measured in the section downstream of the block at midwater depth. The longitudinal and transverse position was occasionally modified to determine the true maximal velocity. Table 1 summarizes the hydraulic flow characteristics during the experiments.

Table 1. Dimensionless Numbers of Flow for Three Channel Widths $(0.25,0.65$, and $1 \mathrm{~m})$

\begin{tabular}{|c|c|c|c|c|c|c|c|c|c|}
\hline \multirow[b]{2}{*}{ Experiment } & \multirow[b]{2}{*}{$D(\mathrm{~mm})$} & \multicolumn{2}{|c|}{$q \times 10^{3}\left(\mathrm{~m}^{2} / \mathrm{s}\right)$} & \multicolumn{2}{|c|}{$\mathrm{F}$} & \multicolumn{2}{|c|}{$\begin{array}{c}\mathrm{R}_{D}=V_{g} D / v \\
\left(\times 10^{3}\right)\end{array}$} & \multicolumn{2}{|c|}{$\begin{array}{c}\mathrm{R}_{h}=V_{g} h / v \\
\left(\times 10^{3}\right)\end{array}$} \\
\hline & & Min & $\operatorname{Max}$ & Min & Max & Min & $\operatorname{Max}$ & Min & $\operatorname{Max}$ \\
\hline $\mathrm{E} 1$ and $\mathrm{E} 8$ to $\mathrm{E} 10$ & 35 & 5 & 110 & 0.25 & 1.3 & 9 & 31 & 10 & 60 \\
\hline E2, E3 & 125 & 5 & 80 & 0.14 & 1.8 & 50 & 110 & 2 & 120 \\
\hline E4 to E7 & 115 & 10 & 90 & 0.36 & 1.6 & 50 & 120 & 30 & 140 \\
\hline
\end{tabular}




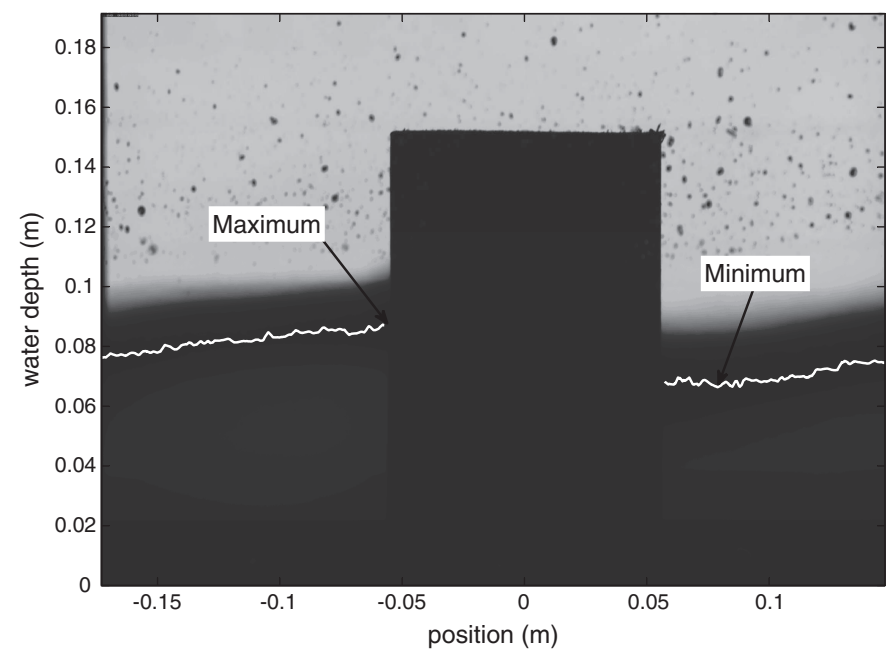

Fig. 3. Filtered picture with smooth bed $C=13 \%$, slope $=3 \%$, $Q=30 \mathrm{~L} / \mathrm{s}$

\section{Flow Pattern}

The experimental observations indicate that the flow pattern was the same (Fig. 5) for a given F even if $h_{*}=h / D$ dependence did occur. However, $h_{*}$ played a role mainly when $h_{*}<1$, because the flow around the block interacted with the bed (see the following). Behind the block, a recirculation zone (near zero velocity) was always present. The width of the zone was approximately equal to the diameter of the block, whereas its length depended on the Froude number. The maximum water level was located upstream of the row of blocks for low Froude numbers and farther downstream for higher Froude numbers. The stream fell and contracted after the narrowest flow section and reached maximum velocity where the water level was the lowest. The location of maximum velocity moved downstream when $\mathrm{F}$ increased. This flow pattern is based on these study measurements and also on results from Baki et al. (2014). Another important dimensionless number is the maximum Froude number, $\mathrm{F}_{\max }=u_{\max } / \sqrt{g h_{d}}$, where $h_{d}$ is the transverse averaged water depth in the downstream section. When the maximum Froude number $\left(F_{\max }\right)$ was greater than 1 , a transitional subsupercritical flow appeared. It is possible to estimate the

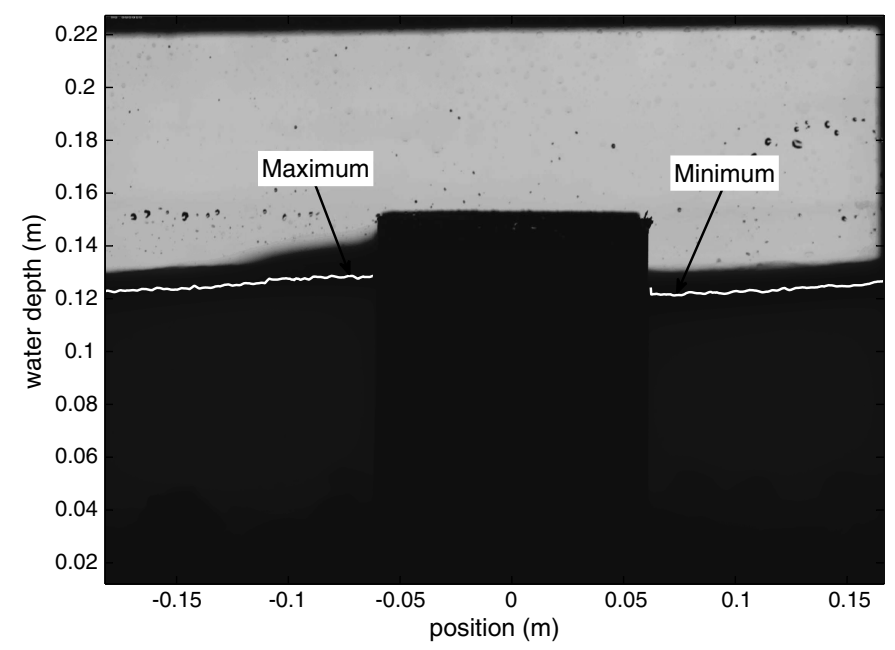

Fig. 4. Filtered picture with rough bed $C=13 \%$, slope $=3 \%$, $Q=30 \mathrm{~L} / \mathrm{s}$

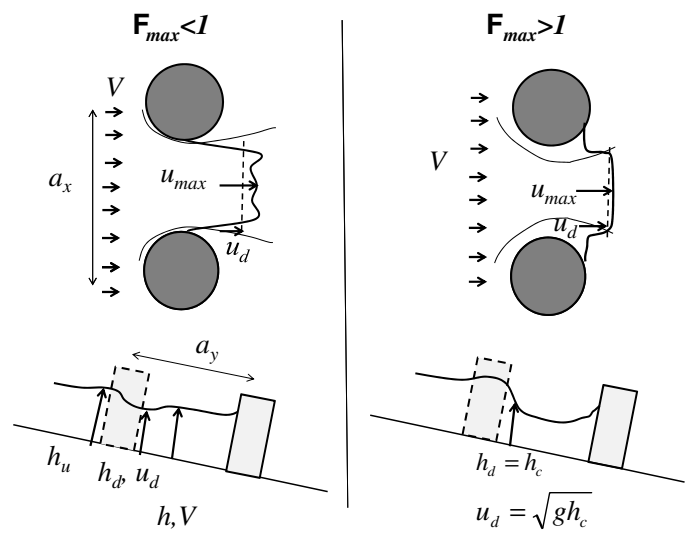

Fig. 5. Flow pattern at low and high local Froude numbers

maximum velocity by assuming $\mathrm{F}_{\max }=1$ because the velocity became almost constant in the $x$-direction in the downstream section. The presence of the downstream blocks prevented the flow from remaining supercritical. Hydraulic jumps appeared in part because the average height was close to the critical height $h_{c}$.

Flow analysis is a means to interpret the experimental results with respect to the deformation of the free surface and maximum velocities. Taking $h_{d}$ as the minimum height and $u_{d}$ as the average velocity at the downstream block, continuity requires that

$$
V_{g} h=u_{d} h_{d}
$$

To estimate $h_{d}$, the head conservation is calculated between the upstream face of the block (zero velocity) and the position of maximum velocity in a downstream section:

$$
\frac{\Delta h}{h}=\frac{h_{u}-h_{d}}{h}=\frac{1}{2} \mathrm{~F}^{2}\left(\frac{u_{\max }^{2}}{V_{g}^{2}}\right)
$$

Experimentally, it is noticed that $h=\left(h_{u}+h_{d}\right) / 2$ (Fig. 6).

For $\mathrm{F}_{\max }<1$ : For low Froude numbers, the maximum downstream velocity can be expressed as

$$
\frac{u_{\max }}{V_{g}}=r \frac{u_{d}}{V_{g}}=r \frac{1}{1-\frac{\Delta h}{2 h}}
$$

where $r=$ ratio between the average velocity at the downstream block $\left(u_{d}\right)$ and the maximum velocity $\left(u_{\max }\right)$. Eq. (3) becomes

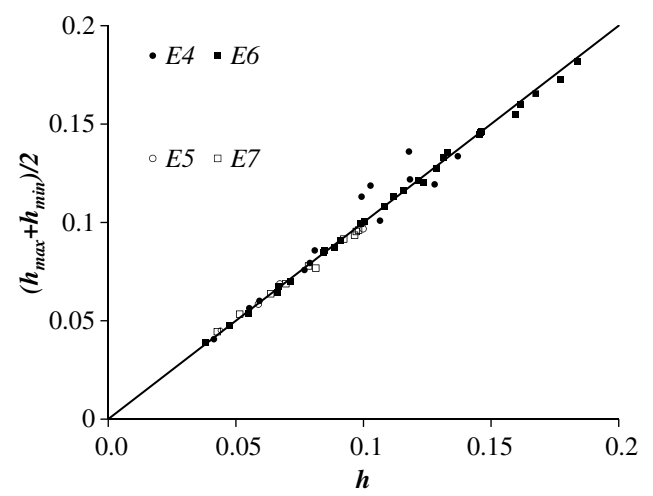

Fig. 6. Relationship between mean water depth $h$ and $h_{\max }$ and $h_{\min }$ 


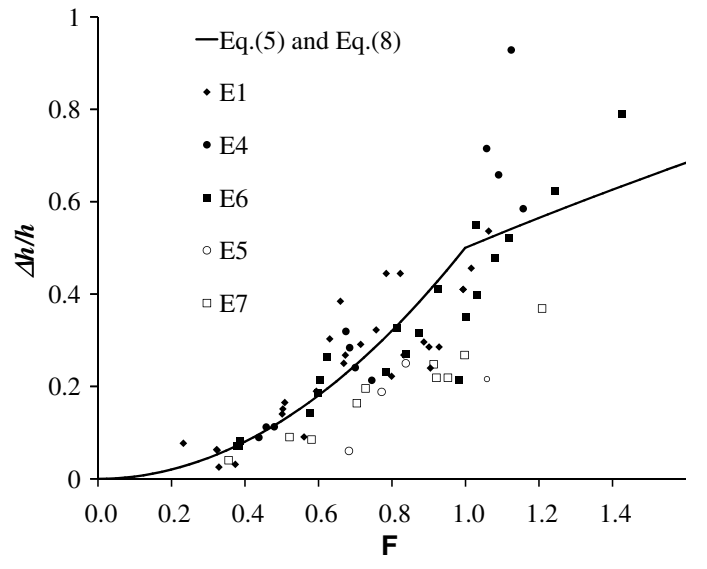

Fig. 7. Free-surface deformation as a function of the Froude number for circular blocks

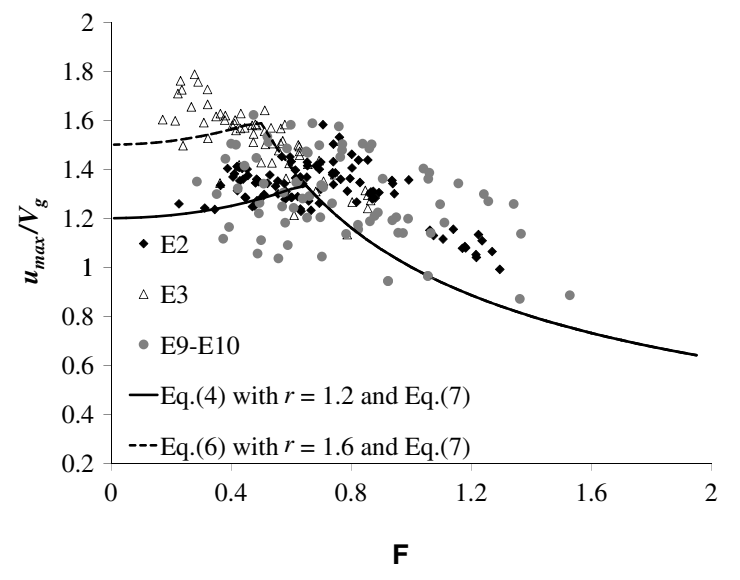

Fig. 8. Normalized maximum velocity measured as a function of the Froude number

$$
\frac{\Delta h}{h}=\frac{1}{2} \mathrm{~F}^{2}\left[\frac{r^{2}}{\left(1-\frac{\Delta h}{2 h}\right)^{2}}\right] \approx \frac{1}{2} \mathrm{~F}^{2}
$$

Experimental results confirmed the previous approximated formula (Fig. 7). They were also used to estimate the ratio $r$ (Fig. 8 and Table 2).

For $\mathrm{F}_{\max }>1$ : To determine the change in the maximum velocity at high Froude numbers, the local Froude number $F_{\text {max }}$ was deemed to reach one in a downstream section of the blocks:

$$
\frac{u_{\max }}{V_{g}} \approx \frac{u_{d}}{V_{g}}=\frac{\sqrt{g h_{d}}}{V_{g}}=\frac{1}{\mathrm{~F}} \sqrt{\frac{h_{d}}{h}}
$$

From Eq. (2), it is possible to conclude that

$$
\frac{u_{\max }}{V_{g}}=\frac{1}{\mathrm{~F}^{2 / 3}}
$$

and

$$
\frac{\Delta h}{h}=\frac{1}{2} \mathrm{~F}^{2 / 3}
$$

To ensure continuous formulation between the subcritical and supercritical flows, the minimum $u_{\max }$ values from Eqs. (4) and (7) and the minimum values for variations in water depth from Eqs. (5) and (8) were used. These equations provide a good approximation of the maximum velocity even if the transition between the two behaviors differs slightly. The excessive simplicity of the flow description may be the reason why velocities are underestimated for large $F$ numbers. The water level downstream was not constant in the section and the flow occasionally contracted, causing an acceleration of the stream $\left(u_{\max }\right.$ differs from $\left.u_{d}\right)$. Nevertheless, on the basis of these measurements, it is possible to observe the influence of the shape of the blocks and the Froude number on the maximum velocity.

\section{Analytical Models}

The model is based on a momentum balance for a volume of fluid in a basic cell $\left(a_{x} * a_{y}\right)$ (Fig. 9). For a uniform flow regime, the spatial variation of momentum and pressure force are zero, the force attributable to gravity causing the flow is balanced by the frictional force of the bottom and the drag force of the macroroughness. For circular blocks, the momentum balance can be written as

$$
F_{\text {drag }}+F_{\text {bed }}=F_{\text {gravity }}
$$

where $F=$ is the component of each force in the longitudinal direction.

The velocity used for drag force is the velocity between blocks, i.e., $V_{g}$. The friction force is only applied where $V=V_{g}$, which justifies the term $\left(a_{x}-D\right) a_{y}-\frac{1}{2} \sigma D^{2}$ (Fig. 10):

$$
\frac{1}{2} C_{d} h D V_{g}^{2}+\frac{1}{2} C_{f}\left[\left(a_{x}-D\right) a_{y}-\frac{1}{2} \sigma D^{2}\right] V_{g}^{2}=g h S\left(a_{x} a_{y}-\sigma D^{2}\right)
$$

\begin{tabular}{|c|c|c|c|c|c|c|c|c|c|c|}
\hline Experiment & Shape & $D(\mathrm{~mm})$ & Bed & $C$ & $a_{x}(\mathrm{~mm})$ & $a_{y}(\mathrm{~mm})$ & Roughness $(\mathrm{cm})$ & $k_{s}(\mathrm{~cm})$ & $C_{d 0}$ & $r$ \\
\hline E1 & Cylinder & 35 & Smooth & 0.13 & 100 & 100 & - & - & 1 & 1.2 \\
\hline E2 & Rounded face & 125 & Rough & 0.13 & 312 & 375 & $3-5$ & 4 & 1.3 & 1.2 \\
\hline E3 & Flat face & 125 & Rough & 0.13 & 312 & 375 & $3-5$ & 4 & 2 & 1.5 \\
\hline E4 & Cylinder & 115 & Smooth & 0.13 & 333 & 333 & - & - & 1 & 1.2 \\
\hline E5 & Cylinder & 115 & Rough & 0.13 & 333 & 333 & $3-5$ & 4 & 1 & 1.2 \\
\hline E6 & Cylinder & 115 & Smooth & 0.16 & 285 & 285 & - & - & 1 & 1.2 \\
\hline E7 & Cylinder & 115 & Rough & 0.16 & 285 & 285 & $3-5$ & 4 & 1 & 1.2 \\
\hline E8 & Cylinder & 35 & Rough & 0.08 & 100 & 160 & $1.5-2$ & 2 & 1 & 1.2 \\
\hline E9 & Cylinder & 35 & Rough & 0.13 & 100 & 100 & $1.5-2$ & 2 & 1 & 1.2 \\
\hline E10 & Cylinder & 35 & Rough & 0.16 & 80 & 95 & $1.5-2$ & 2 & 1 & 1.2 \\
\hline
\end{tabular}

$$
\frac{1}{2} C_{d} \frac{C h}{D} V_{g}^{2}+\frac{1}{2} \alpha C_{f} V_{g}^{2}=g h S(1-\sigma C)
$$

Table 2. Experimental Flow Conditions for the Three Channel Widths 


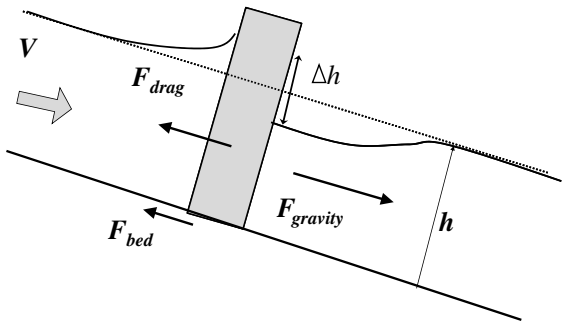

Fig. 9. Momentum balance

where $\alpha=\left\{\left[1-\sqrt{C\left(a_{y} / a_{x}\right)}\right]-(1 / 2) \sigma C\right\} ; h=$ average water depth above bed roughness; $S=$ slope; $C_{d}=$ drag coefficient of the block; $C_{f}=$ bed-friction coefficient; and $\alpha=$ coefficient taking into account the spatial heterogeneity of the velocity. The $\alpha$ value could be determined theoretically by analyzing the flow pattern. For the cylindrical form of the blocks, $\sigma$ is equal to $\pi / 4$, and for a square block, $\sigma=1$. The influence of this term is relatively low as far as the mean velocity calculation is concerned.

In dimensionless form, Eq. (11) becomes

$$
C_{d} C h_{*} \frac{(1+N)}{(1-\sigma C)} \mathrm{F}^{2}=2 S
$$

with $h_{*}=h / D, N=\left(\alpha C_{f}\right) /\left(C_{d} C h_{*}\right)$, and $\mathrm{F}=V_{g} / \sqrt{g h}$.

The factor $N$ is introduced to identify the preponderant phenomenon. In a fishpass, there may be $N$ values on the order of 1. Aberle et al. (2010) showed the importance of bed friction, inaccurately computing the discharge through an array of rigid obstacles. Eq. (12) clearly shows that the flow depends on the Froude number, and the Froude similarity can be applied because $C_{d}$ and $C_{f}$ are not dependent on the Reynolds number $\mathrm{R}_{h}=V_{g} h / v$. This is probably true because the Reynolds numbers are higher than 10,000 for the physical model and 50,000 for full-scale fishpasses. In this approach, it is assumed that the drag coefficient $C_{d}$ is constant regardless of the flow pattern. This hypothesis will be discussed in the following sections. Finally, the mean velocity may be calculated as

$$
V=\left(1-\sqrt{\frac{a_{y}}{a_{x}} C}\right) \sqrt{\frac{2 g D S(1-\sigma C)}{C_{d} C(1+N)}}
$$

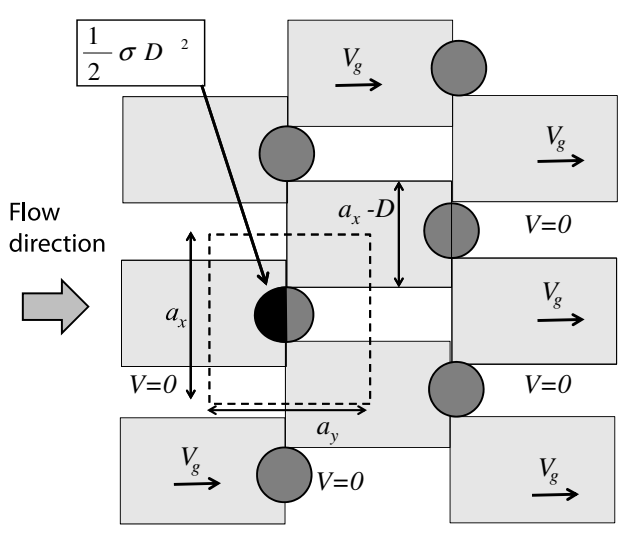

Fig. 10. Assumption of flow pattern to compute $\alpha$

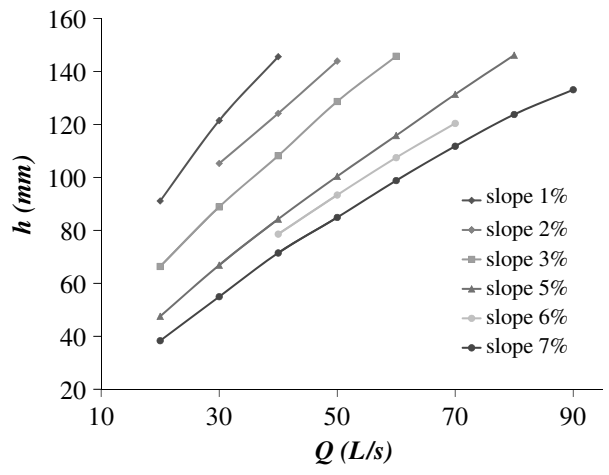

Fig. 11. Averaged water depth as a function of discharge in the E6 experiments

\section{Experimental Results}

The primary relationship for nature-like fishpass design is the stage-discharge relationship (Fig. 11). It could be determined with sufficient information about the drag and friction coefficients [Eq. (13)]. However, it was noticed that a direct determination of $C_{d}$ derived from Eq. (14) does not lead to the standard value of $C_{d}$, i.e., 1 for cylinder and 2 for flat-faced block (Fig. 12). The error bars on Fig. 12 correspond to the estimated measurement accuracy $(+/-5 \mathrm{~mm})$ :

$$
C_{d}=\frac{1}{C h_{*}}\left[\frac{2 S(1-\sigma C)}{\mathrm{F}^{2}}-\alpha C_{f}\right]
$$

where the drag coefficient $C_{d}$ is directly measured without correction. For similar Froude numbers, $C_{d}$ can take on very different values, although the concentration is identical. To understand the parameter influencing the drag, the following procedure is adopted. A smooth bed was assumed for the calculation of $C_{d}$, i.e., $C_{f}$ was negligible. The influence of the Froude number was measured by varying the slope. Experiments E1 and E4 were conducted with the same geometric ratio and with Froude similarity. But the Reynolds number differs from one order of magnitude for the two series of measurements. The same comparison can be done between E5 and E9. The same behavior of drag coefficient was noticed whatever the Reynolds number was. When $C_{d}$ had been correctly determined, the roughness height $k_{s}$ was adjusted with the rough experiments as explained in the following section.

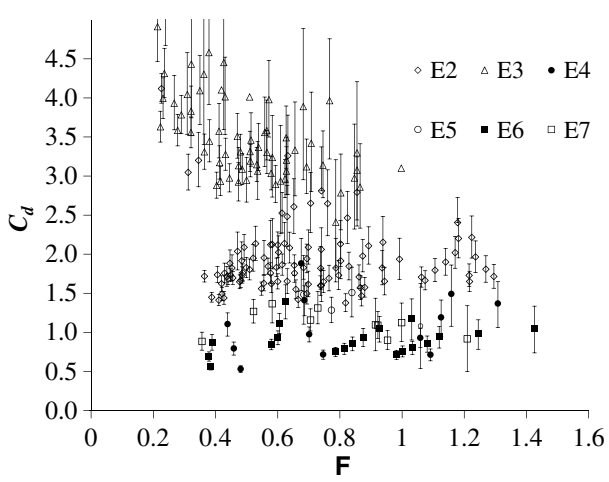

Fig. 12. Drag coefficient from Eq. (14) (without correction function) 


\section{Bed Friction}

A good estimation of the bed-friction coefficient is necessary to validate the present approach. For the experiments with a smooth bed, the flow is also supposed to be smooth. Then $C_{f}$ is estimated using the Blasius formula, which represents the friction coefficient over a flat plate $\left(C_{f}=0.3164 / 4 \mathrm{R}_{h}^{-0.25}\right)$. For rough beds, the formula of Rice et al. (1998) [Eq. (15)] is used. The roughness height $k_{s}$ is adjusted to reproduce the conditions of the experiments with low water depth:

$$
C_{f}=\frac{2}{\left[5.1 \log \left(\frac{h}{k_{s}}\right)+6\right]^{2}}
$$

\section{Drag Coefficient}

For a smooth bed, $N \ll 1$, high values of $C_{d}$ cannot be explained by an incorrect estimation of $C_{f}$. Ishikawa et al. (2000) have shown that the correlation between $\mathrm{R}$ and $C_{d}$ is not trivial. Cheng and Nguyen (2011) propose a Reynolds number based on a hydraulic radius. They show that $C_{d}$ varies with $\mathrm{R}$.

For the experiments presented here, the flow is fully developed $\left(\mathrm{R}_{D}>1,000\right)$. So, the hypothesis of relationship between $C_{d}$ and the Reynolds number cannot be made. Moreover, experimentally, the dependency for $C_{d}$ on the Reynolds number is not obvious. As the goal of the study is to provide a relationship for design that is easy to use, the variations are assumed to be a function of the concentration, the Froude number, and the presence of the bed. This assumption appears adequate to explain the experimental results. The drag coefficient is then expressed as

$$
C_{d}=C_{d 0} f_{C}(C) f_{\mathrm{F}}(\mathrm{F}) f_{h_{*}}\left(h_{*}\right)
$$

where $C_{d 0}=$ drag coefficient of a single, infinitely long block with $\mathrm{F} \ll 1$. The function $f_{C}(C)$ is derived from the literature and $f_{\mathrm{F}}(\mathrm{F})$ from the analysis of the average velocity between the blocks. Only the function $f_{h *}\left(h_{*}\right)$ is determined experimentally.

\section{Influence of Macro-Roughness Concentration}

The determination of $f_{C}(C)$ is based on the model proposed by Nepf (1999). For turbulent flows $\left(R_{D}>200\right)$, Nepf (1999) points out that the drag coefficient should decrease as the concentration increases. The model proposed produces the result $0.4<C_{d}<0.65$ in the range of typical concentrations for fishpasses $(0.08<C<0.25)$ (Fig. 13). A simplified function $f_{C}(C)$ specific to the presents configurations was proposed. That is consistent with the experimental results [Eq. (17)]. It is obtained with a linear

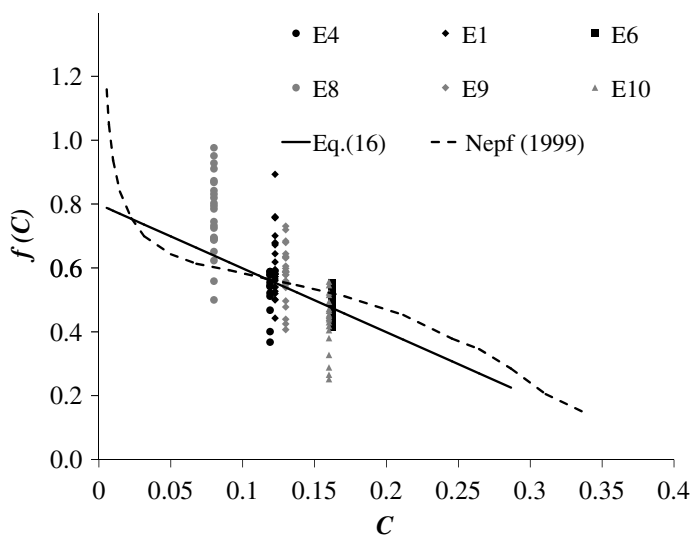

Fig. 13. Corrected function as a function of the concentration; comparison with results of Nepf (1999) regression of the model between $C=0.01$ and 0.3 . A linear fitting is sufficient, and the error involved by this assumption is negligible (5\% on $q$ ). The experimental results, depicted on the Fig. 13, are corrected with $f_{\mathrm{F}}(\mathrm{F})$ [Eq. (19)] and $f_{h_{*}}\left(h_{*}\right)$ [Eq. (20)] described as follows:

$$
f_{C}(C)=0.8-2 C
$$

\section{Influence of Froude Number}

To take into account the influence of the Froude number on the drag calculation, the reference velocity for the drag term is $u_{d}$ (Fig. 5) instead of $V_{g}$. Energy dissipation occurs mainly in the stream and in the wake, which is why the hydrodynamic characteristics are taken at the downstream blocks to compute the drag force. Hence the drag term is expressed as

$$
\mathrm{F}_{\mathrm{drag}}=\frac{1}{2} C_{d} \frac{C h}{D} u_{d}^{2}=\frac{1}{2} C_{d} \frac{C h}{D} V_{g}^{2} f_{\mathrm{F}}(\mathrm{F})
$$

Combining Eqs. (2) and (18) leads to

$$
f_{\mathrm{F}}(\mathrm{F})=\left(\frac{u_{d}}{V_{g}}\right)^{2}=\min \left(\frac{1}{1-\frac{\mathrm{F}^{2}}{4}}, \frac{1}{\mathrm{~F}^{2 / 3}}\right)^{2}
$$

The assumptions concerning the reference velocity for the calculation of $C_{d}$ would appear to be validated by these experiments (Figs. 14 and 15), and the importance of the correct reference velocity

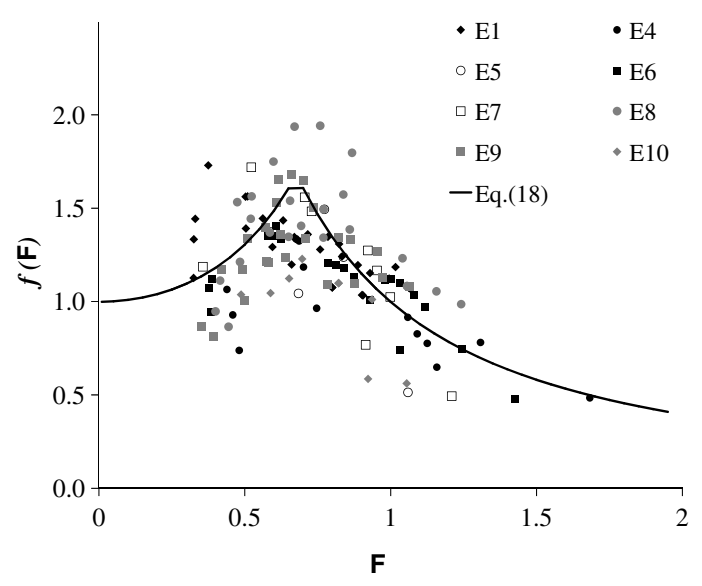

Fig. 14. Correction function as a function of $F$ for circular blocks

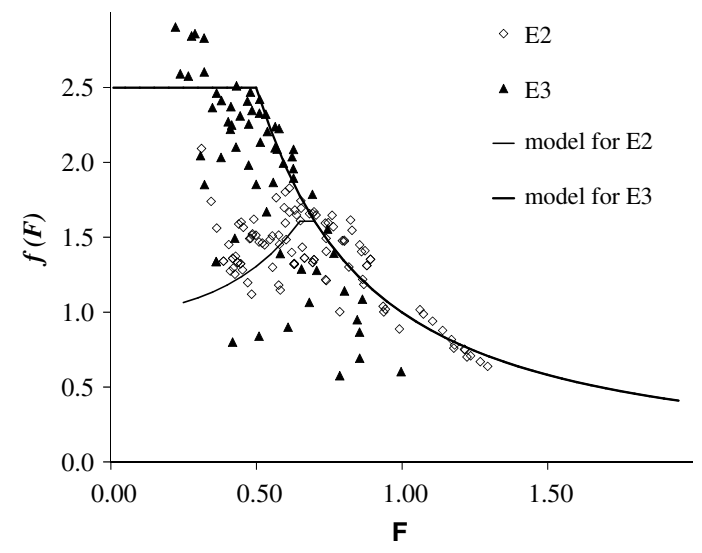

Fig. 15. Correction function as a function of $F$ for rounded and flat blocks 
for the calculation of drag has been demonstrated. Underestimation of $f_{\mathrm{F}}(\mathrm{F})$ is directly related to the fact that $u_{\max }$ is also underestimated when $F_{\max }>1$ (Fig. 8). The model correctly reproduces the general trends, and there is a good congruence between the experimental and theoretical results deduced from Eq. (19). The data dispersion is greater for the experiments with an approximate water-level measurement method (E1, E2, E3, E8, and E9) because a one-point measurement is less accurate than averaging over the cell. In the case of cylindrical blocks, the correction caused by $f_{\mathrm{F}}(\mathrm{F})$ is significant only for $\mathrm{F}>1$. For other block shapes, it is necessary to carefully consider the supercritical flow. The drag force can be over- or underestimated by a factor of 2 . The supercritical behavior occurs for a lower overall Froude number $(F)$. This may be attributable to the contraction caused by the shape of the blocks, which results in higher velocities. To model this behavior, the correction function applied to $f_{\mathrm{F}}(\mathrm{F})=2.5$ is limited, as indicated by the experimental values (Fig. 15).

\section{Influence of the Bed}

The majority of the drag coefficient measurements were made on obstacles with an infinite height. But, when $h_{*}$ is relatively low, the flow around the obstacle modifies the standard value of $C_{d}$. The approach presented here is purely empirical, because the characteristics of a three-dimensional flow where $\mathrm{F}>1$ and $h_{*} \approx 1$ are unknown. Fig. 16 shows that during all the experiments under consideration, $C_{d}$ increases when $h_{*}$ decreases. Experiments on smooth beds show that this behavior is not attributable to an incorrect determination of $C_{f}$. Moreover, the same trend is observed for different Reynolds numbers (see E1 and E4 in Table 2). Consequently, in a first approximation, the geometric parameter $h_{*}$ would appear to be the most relevant in explaining this behavior. Oertel et al. (2011) observed the same behavior for a cylinder $(D=6 \mathrm{~cm}$, and $1.5 \mathrm{~cm}<h<5.6 \mathrm{~cm}$ ). In this paper, the variation of $C_{d}$ is correlated with the Reynolds number, but it can also be interpreted as a function of $h / D$, in which case their measurements agree with the present observations. Because the flow was supercritical, the drag coefficient was recalculated using the measured force and the critical height $h_{c}=\left(q^{2} / g\right)^{1 / 3}$. This implies using the correction $f_{\mathrm{F}}(\mathrm{F})$.

Finally, the correlation is

$$
f_{h_{*}}\left(h_{*}\right)=1+\frac{0.4}{h_{*}^{2}}
$$

Only the experiments with an accurate experimental determination of $h$ (E4 to E7) are used for fitting. Although corrected functions are not used, Baki et al. (2014) also measured a similar trend

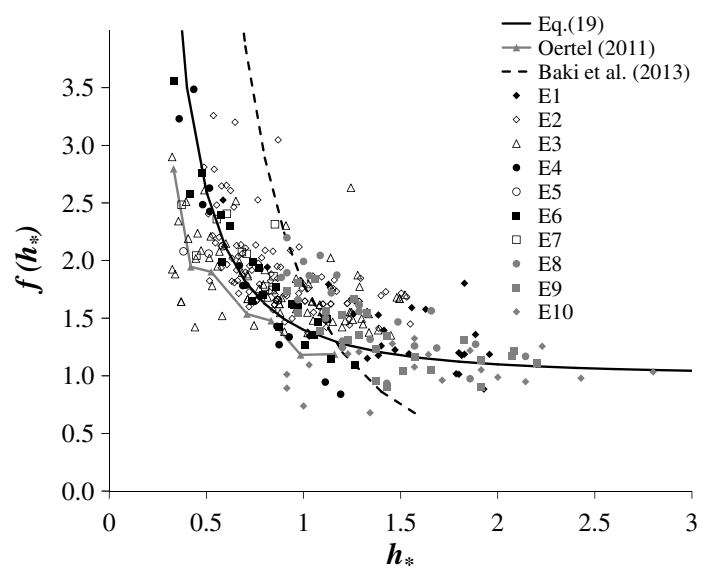

Fig. 16. Correction function with relative water depth in the variation of $C_{d}$ as a function of $h_{*}$. The correction function can easily be linked to the presence of the bed, which changes the distribution of velocity and pressure around the block. In particular, the presence of a horseshoe vortex at the foot of the block (Sadeque et al. 2008; Singha and Balachandar 2011) increases when the water level decreases. The recirculation zone is also threedimensional, as was highlighted by Akilli and Rockwell (2002).

In the momentum balance, the pressure force on the block was neglected; however, it can be higher on the upstream side than on the downstream side. The proposed correlation [Eq. (20)] can be partially explained by this phenomenon. Because the pressure was not measured, the overall correction $f_{h_{*}}\left(h_{*}\right)$ is applied.

\section{Hydraulic Resistance}

To analyze the experimental results, a standardized rate per meter of width $q_{*}$ was used to achieve the design objective:

$$
q_{*}=\frac{q}{\sqrt{g} D^{3 / 2}}=h_{*}\left(1-\sqrt{\frac{a_{y}}{a_{x}} C}\right) \sqrt{\frac{2 S(1-\sigma C)}{C_{d} C(1+N)}}
$$

The flow in the channel can depend on either the drag or the bed friction. In practice, a nature-like fishpass is inclined sideways to facilitate the passage of small fish species. Consequently, the water depth may be small relative to bed roughness, and $N$ may take on a wide range of values. When $N \ll 1$, the stage-discharge relationship is linear because the velocity $V$ does not depend on $h_{*}$.

The use of the term $f_{\mathrm{F}}(\mathrm{F})$ for the flow calculation does not directly produce a value of $q_{*}$ depending on $h_{*}$ [Eq. (21)]. To simplify the expression for $q_{*}$, the correction for the calculation of flow rates is not applied: $f_{\mathrm{F}}(\mathrm{F})=2$ for flat-faced blocks, $f_{\mathrm{F}}(\mathrm{F})=1$ for cylinders, and $f_{\mathrm{F}}(\mathrm{F})=1.5$ for the intermediate shape (E2 experiments). Figs. 17 and 18 show that this simplification has little influence on the estimated discharge. The difference is noticeable only for $\mathrm{F}>0.8$, which is not a nature-like fishpass configuration. The error in the estimation of the flow rate is less than $10 \%$ for $0.08<C<0.2$ and $0<S<7 \%$. Moreover, it is necessary to add the uncertainty attributable to the $C_{d}$ value. For a natural block shape, a mean value of $C_{d}=1.5$ may be used. Eq. (13) indicates that the total discharge can vary by $20 \%$ if the real $C_{d}$ is between 1 and 2. Fortunately, for concrete blocks with a defined shape, the uncertainty is significantly reduced.

Similar to the discharge, the error in the maximal velocity estimation is less than $20 \%$ (Fig. 19), and is reduced (10\%) when $F<0.8$. The velocity measured for a rough bed can also differ from the model. This could be attributable to the vertical distribution of

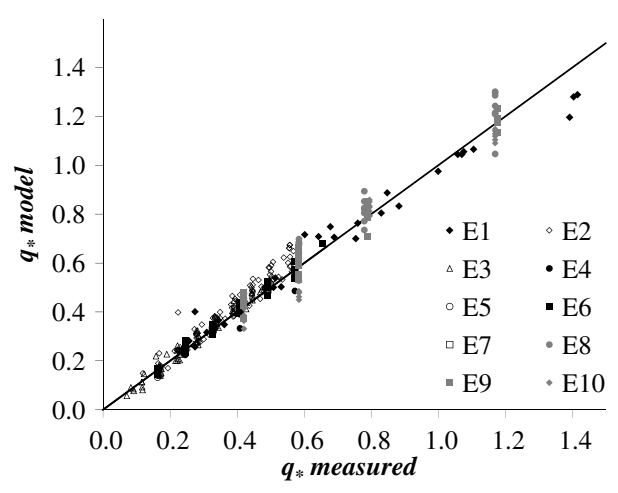

Fig. 17. Comparison of specific discharge between model and measurements 


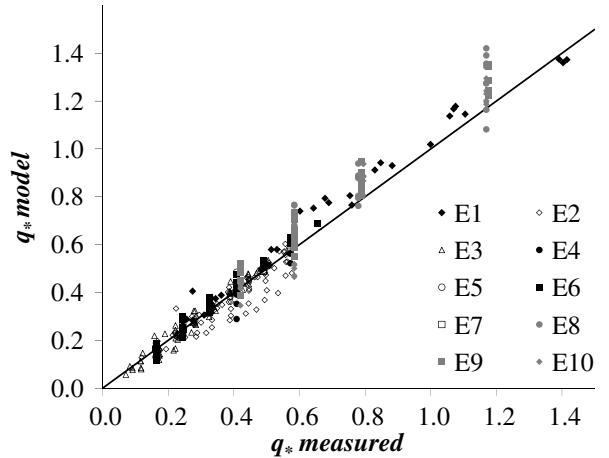

Fig. 18. Comparison of discharge between simplified model $\left[f_{\mathrm{F}}(\mathrm{F})=1,1.5\right.$, or 2$]$ and measurements

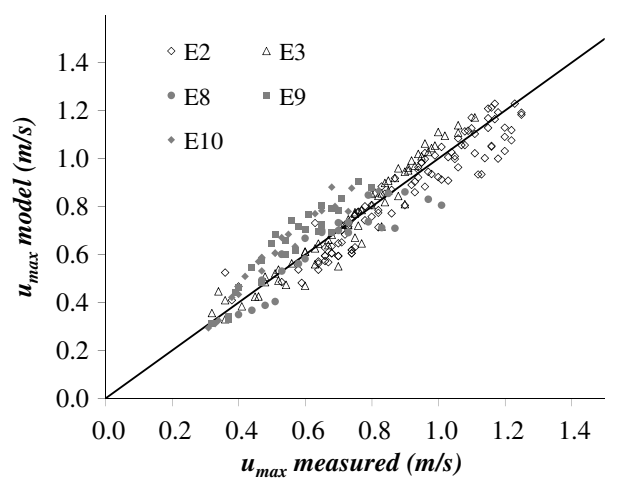

Fig. 19. Comparison of maximum velocity between the simplified model $\left[f_{\mathrm{F}}(\mathrm{F})=1,1.5\right.$, or 2$]$ and measurements

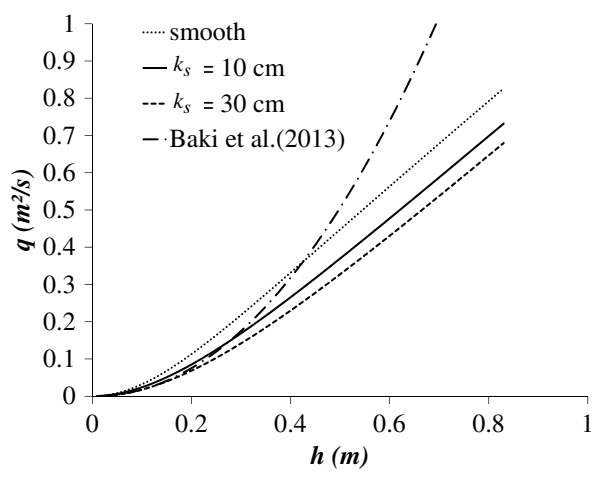

Fig. 20. Influence of bed roughness in a full-scale fishpass (slope $=5 \%, D=50 \mathrm{~cm}, C=13 \%$ )

velocity. The influence of a rough bed was also quantified. At first, it was planned to increase the dissipation in the pass by adding bed roughness. Fig. 20 shows the evolution of the stage-discharge relationship for a pass the size of which depends on the size of bed roughness.

The presence of roughness slightly decreased the flow per unit width $q$. The contribution of bed roughness would appear to be negligible. However, it may locally reduce velocity near the bed. This modifies the organization of the flow within the wake that may be favorable to the passage of small species. Studies on the vertical velocity profiles are underway to investigate this point. The present results are compared with the formula of Baki et al.

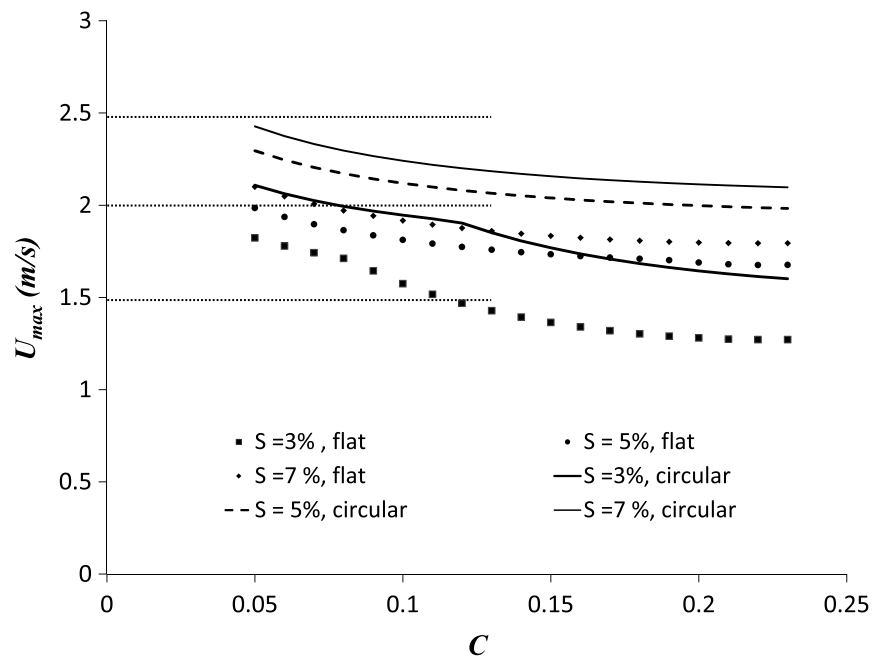

Fig. 21. Maximum velocity in a full-scale fishpass (slope $=5 \%$, $D=50 \mathrm{~cm}, C=13 \%$ ); comparison with the maximum velocity of several fish species (horizontal dashed lines)

(2014). The two formulas provide a similar specific discharge up to $h / D=1$ because the block in Baki et al. (2014) is then submerged, whereas it remains emergent in the formula proposed. At low water depth, the same behavior is observed but it is produced by bed friction in the present model, whereas it is attributable to $C_{d}$ in Baki et al. (2014).

Fig. 21 presents the maximum velocity calculated in full-scale fish passes as a function of concentration for various slopes and block shapes, at fixed water depth $(h=D=0.5 \mathrm{~m})$. This water depth is higher than the recommended minimum water depths, 0.2 to $0.4 \mathrm{~m}$, depending of fish species, and is equal to the height of blocks fluently implemented. In France, it is recommended that the maximum velocity should not exceed $2.5 \mathrm{~m} / \mathrm{s}$ for Atlantic salmon, sea trout, and sea lamprey; $2.0 \mathrm{~m} / \mathrm{s}$ for shad, brown trout, grayling, and rheophilic cyprinids; and $1.5 \mathrm{~m} / \mathrm{s}$ for small species (Larinier et al. 2006). These velocities are similar to those in the jet in pool-type fishpasses obtained with recommended drops between pools (Larinier et al. 2002).

A ramp with rough bed and rounded protruding macroroughness at $C=13 \%$ may be passable by salmon, sea trout, and sea lamprey for slopes up to $10 \%$; by shad, brown trout, grayling, and rheophilic cyprinids for slopes up to 5\%; and by small species for slopes up to $2.5 \%$. Flat-faced blocks produce lower maximum velocities compared with rounded blocks and may allow increasing passable slopes by $30 \%$, for a given concentration. However, this advantage is offset on one hand by a lower discharge, and thus a lower attractiveness for a fishpass, and on the other hand by a higher sensitivity to clogging. The preceding slopes, only deduced from criteria on maximum velocity, need to be confirmed. Further studies will focus on the stage-discharge relationship for submerged macroroughness and on the influence of velocity distributions and turbulence levels on the passability of fishpasses.

\section{Conclusions}

Block arrays with higher Froude and Reynolds numbers than those used for emergent vegetation are studied experimentally. Compared with previous research, these configurations have steep slopes and relatively large block diameters. The influence of block shapes and 
their concentration are specifically designed. The aim of this study was to provide a stage-discharge relationship for fishpass configurations. The study also produced knowledge on the gravitational effects in shallow flows with blocks. The analysis method is based on the total hydraulic resistance generated by emergent obstacles. However, the formulation was adapted to take into account the effects of interaction between the wakes and the bed. An experimental correlation was proposed. It would appear more general in application than those based on the Reynolds number, and it depends exclusively on the aspect ratio $h / D$. In addition, supercritical flow can occur in the studied configurations, unlike in classic river flows. This transition involves a modification of the drag-force reference velocity. The maximum velocity, which is crucial for passability, can be expressed for the subcritical and supercritical regimes as a function of the concentration and the slope.

Finally, an analytical model to quantify the impact of block geometry and to compute the hydraulic resistance of the fishpass is proposed. The submitted stage-discharge relationship will be useful for the design of a nature-like fishpass with a rough bed and protruding macroroughness evenly distributed in staggered rows.

\section{Notation}

The following symbols are used in this paper:

$a_{x}=$ width of a cell (perpendicular to flow) (m);

$a_{y}=$ length of a cell (parallel to flow) (m);

$C=$ block concentration;

$C_{d}=$ drag coefficient of a block under the actual flow conditions;

$C_{d 0}=$ drag coefficient of a block considering a single block infinitely high with $\mathrm{F} \ll 1$;

$C_{f}=$ bed-friction coefficient;

$D=$ block length (in front of the flow) (m);

$\mathrm{F}=$ Froude number based on $h$ and $V_{g}$;

$F=$ force in the longitudinal direction;

$\mathrm{F}_{\max }=$ local Froude number based on $h_{d}$ and $u_{\max }$;

$g=$ gravitational constant $\left(\mathrm{m} / \mathrm{s}^{2}\right)$;

$h=$ mean water depth in a cell $(\mathrm{m})$;

$h_{c}=$ critical depth in the downstream section (m);

$h_{d}=$ averaged water depth at the downstream cross section $(\mathrm{m})$;

$h_{u}=$ water depth in front of a block (m);

$h_{*}=$ dimensionless water depth $(h / D)$;

$k_{s}=$ height of roughness $(\mathrm{m})$;

$N=$ ratio between bed-friction force and drag force in a cell;

$Q=$ total discharge $(\mathrm{L} / \mathrm{s})$;

$q=$ specific discharge per unit width $\left(\mathrm{m} / \mathrm{s}^{2}\right)$;

$r=$ ratio between $u_{\max }$ and $u_{d}$;

$\mathrm{R}_{D}=$ Reynolds number based on $D$ and $V_{g}$;

$\mathrm{R}_{h}=$ Reynolds number based on $h$ and $V_{g}$;

$S=$ bed slope;

$u_{d}=$ averaged velocity in the downstream section $(\mathrm{m} / \mathrm{s})$;

$u_{\max }=$ maximum longitudinal velocity in a cell $(\mathrm{m} / \mathrm{s})$;

$V=$ averaged velocity of the total cross section $(\mathrm{m} / \mathrm{s})$;

$V_{g}=$ averaged velocity in the section between two blocks $(\mathrm{m} / \mathrm{s})$;

$\alpha=$ coefficient of the velocity nonuniformity in a cell;
$\Delta h=$ variation in the water depth $\left(h_{u}-h_{d}\right)(\mathrm{m}) ;$ and $\sigma=$ ratio between the block area in the $x, y$ plane and $D^{2}$.

\section{References}

Aberle, J., Järvelä, J., Schoneboom, T., and Dittrich, A. (2010). "Flow resistance of rigid and flexible emergent vegetation revisited." Proc., 1 st European IAHR Congress, Edinburg, U.K.

Akilli, H., and Rockwell, D. (2002). "Vortex formation from a cylinder in shallow water." Phys. Fluids, 14(9), 2957-2967.

Baki, A., Zhu, D., and Rajaratnam, N. (2014). "Mean flow characteristics in a rock-ramp type fishpass" J. Hydraul. Eng., 140(2), 156-168.

Cheng, N., and Nguyen, H. (2011). "Hydraulic radius for evaluating resistance induced by simulated emergent vegetation in open-channel flows." J. Hydraul. Eng., 10.1061/(ASCE)HY.1943-7900.0000377, 995-1004.

Ferro, V. (1999). "Friction factor for gravel-bed channel with high boulder concentration." J. Hydraul. Eng., 10.1061/(ASCE)0733-9429(1999) 125:7(771), 771-778.

Heimerl, S., Krueger, F., and Wurster, H. (2008). "Dimensioning of fish passage structures with perturbation boulders." Hydrobiologia, 609(1), 197-204

Huai, W., Chen, Z., Han, J., Zhang, L., and Zeng, Y. (2009). "Mathematical model for the flow with submerged and emerged rigid vegetation." J. Hydrodyn., Ser. B, 21(5), 722-729.

Ishikawa, Y., Mizuhara, K., and Ashida, S. (2000). "Effect of density of trees on drag exerted on trees in river channels." J. For. Res., 5(4), 271-279.

James, C. S., Birkhead, A. L., Jordanova, A. A., and O'Sullivan, J. J. (2004). "Flow resistance of emergent vegetation." J. Hydraul. Res., 390-398.

Larinier, M., Courret, D., and Gomes, P. (2006). "Technical guide to the concept on nature-like fishways." Rapport GHAAPPE RA.06.05-V1, 5, ONEMA, Paris, France (in French).

Larinier, M. F., Travade, F., and Porcher, J. (2002). "Fishway: Biological basis, design criteria and monitoring." Bull. Fr. Pêche Piscic., 364, 208.

Nepf, H. M. (1999). "Drag, turbulence, and diffusion in flow through emergent vegetation." Water Resour. Res., 35(2), 479-489.

Oertel, M., Peterseim, S., and Schlenkhoff, A. (2011). "Drag coefficients of boulders on a block ramp due to interaction processes." J. Hydraul. Res., 49(3), 372-377.

Oertel, M., and Schlenkhoff, A. (2012). "Crossbar block ramps: Flow regimes, energy dissipation, friction factors, and drag forces." J. Hydraul. Eng., 10.1061/(ASCE)HY.1943-7900.0000522, 440-448.

Pagliara, S., and Chiavaccini, P. (2006). "Flow resistance of rock chutes with protruding boulders." J. Hydraul. Eng., 10.1061/(ASCE)07339429(2006)132:6(545), 545-552.

Rice, C. E., Kadavy, K. C., and Robinson, K. M. (1998). "Roughness of loose rock riprap on steep slopes.” J. Hydraul. Eng., 10.1061/(ASCE) 0733-9429(1998)124:2(179), 179-185.

Rowinski, P. M., and Kubrak, J. (2002). "A mixing-length model for predicting vertical velocity distribution in flows through emergent vegetation." Hydrol. Sci. J., 47(6), 893-904.

Sadeque, M., Rajaratnam, N., and Loewen, M. (2008). "Flow around cylinders in open channels." J. Eng. Mech., 10.1061/(ASCE)0733-9399 (2008)134:1(60), 60-71.

Singha, A., and Balachandar, R. (2011). "Structure of wake of a sharpedged bluff body in a shallow channel flow." J. Fluid. Struct., 27(2), 233-249.

Tinoco, R., and Cowen, E. (2013). "The direct and indirect measurement of boundary stress and drag on individual and complex arrays of elements." Exp. Fluids, 54(4), 1-16. 